\title{
Reproductive cycles in females
}

\begin{abstract}
The reproductive system in females consists of the ovaries, uterine tubes, uterus, vagina and external genitalia. Periodic changes occur, nearly every one month, in the ovary and uterus of a fertile female. The ovarian cycle consists of three phases: follicular (preovulatory) phase, ovulation, and luteal (postovulatory) phase, whereas the uterine cycle is divided into menstruation, proliferative (postmenstrual) phase and secretory (premenstrual) phase. The secretory phase of the endometrium shows thick columnar epithelium, corkscrew endometrial glands and long spiral arteries; it is under the influence of progesterone secreted by the corpus luteum in the ovary, and is an indicator that ovulation has occurred.
\end{abstract}

Volume 2 Issue 2 - 2016

\section{Heshmat SW Haroun \\ Faculty of Medicine, Cairo University, Egypt}

Correspondence: Heshmat SW Haroun, Professor of Anatomy and Embryology, Faculty of Medicine, Cairo University, Egypt, Email heshmatsabet@hotmail.com

Received: June 30, 2016 | Published: July 21, 2016

Keywords: ovarian cycle, ovulation, menstrual cycle, menstruation, endometrial secretory phase

\section{Introduction}

The fertile period of a female extends from the age of puberty (11-14years) to the age of menopause (40-45years). A fertile female exhibits two periodic cycles: the ovarian cycle, which occurs in the cortex of the ovary and the menstrual cycle that happens in the endometrium of the uterus. The phases of the menstrual cycle are under the control of the hormones secreted during the different phases of the ovarian cycle.

\section{A review of the female reproductive system}

\section{The ovaries}

Each ovary lies at the sidewall of the pelvis, hanging by a mesovarium from the posterior aspect of the broad ligament, close to the uterine (Fallopian) tube. It has the shape and size of an almond and is almost $1 / 2$ the size of the testis.

\section{The uterine (fallopian) tubes}

Each tube measures about $10 \mathrm{~cm}$ long. Each opens medially into the uterine cavity and laterally into the peritoneal cavity. The uterine tube is lined with ciliated columnar epithelium and is formed of four parts. Its Infundibulum has a mouth opening guarded by fimbriae of which the ovarian fimbria is the longest as it adheres to the ovary. The ampulla is a wide part with a thin wall, the Isthmus is a narrow part with a thick wall, and the interstitial (intramural) part lies inside the wall of the uterus.

\section{The uterus}

It has the shape of a flattened pear in nullipara where it measures $3 \times 2 \times 1$ inches. It is formed of three parts. The fundus is the part bulging above the attachments of the uterine tubes. Its body is the main part, being narrowed below to form the isthmus. Its cervix is about one inch long and has a supravaginal part and a vaginal part (portio vaginalis) that bulges into the vagina and is surrounded by the vaginal fornices. The orifice of the cervical canal into the vagina is called the external os. The cavity of the uterus is very narrow, being flattened anteroposteriorly. It communicates with the cervical canal through the internal os. The wall of the uterus is very thick consisting of three layers. The endometrium is the mucous membrane lining and it contains the uterine glands. The myometrium is formed of many smooth muscle fibres arranged in different directions. The perimetrium is the peritoneal covering of the uterus.

\section{The vagina}

It is the birth and copulatory canal. Its anterior wall measures $7.5 \mathrm{~cm}$ and its posterior wall $9 \mathrm{~cm}$ long. The hymen in virgins closes its lower (vestibular) end. It has different morphological types: annular, septate, cribriform, fleshy elastic and imperforate.

\section{The external genitalia}

They include the labia majora, labia minora and the clitoris (Figure $1)$.

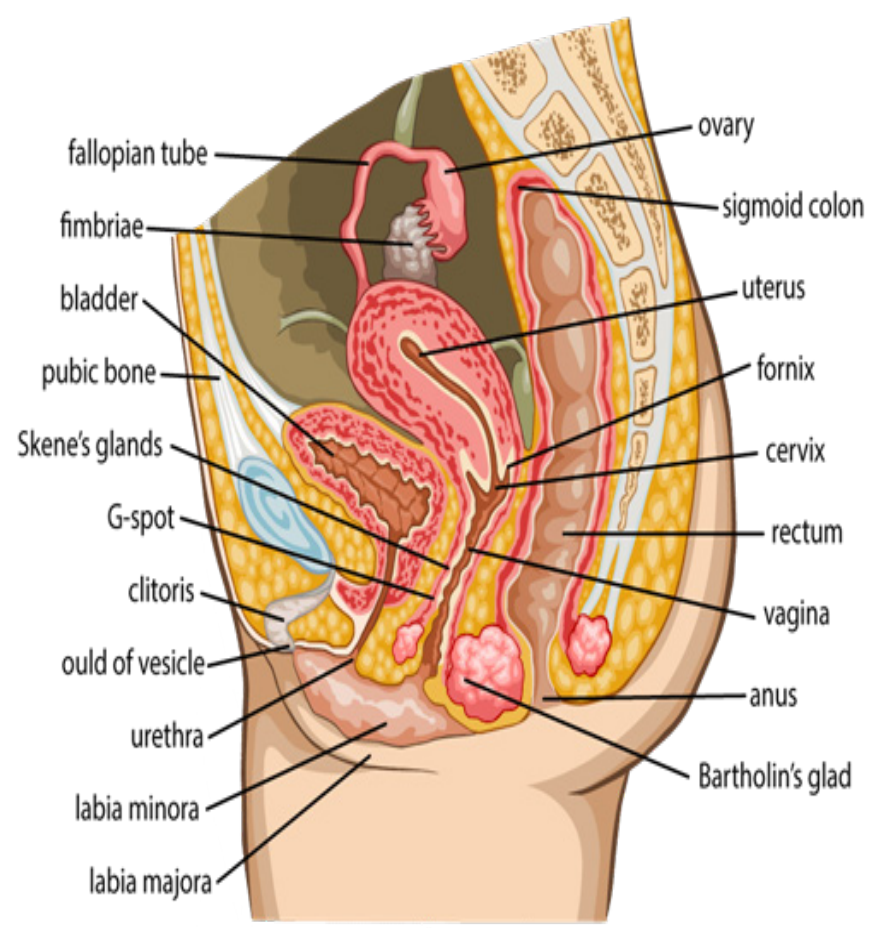

Figure I Female reproductive system. 


\section{The female reproductive cycles}

They are the periodic (rhythmic) changes that occur once about every lunar month (28days) in the female reproductive organs (ovary and uterus) during the reproductive (fertile) period from puberty (11-14years) until menopause (40-45years). They include the ovarian cycle and the uterine (endometrial, menstrual) cycle. ${ }^{1-4}$

\section{The ovarian cycle}

It occurs in the cortex of the ovary. It has three phases: the follicular phase (in the first half of the cycle), ovulation (at about the middle of the cycle) and the luteal phase (in the second half of the cycle) (Figure 2).

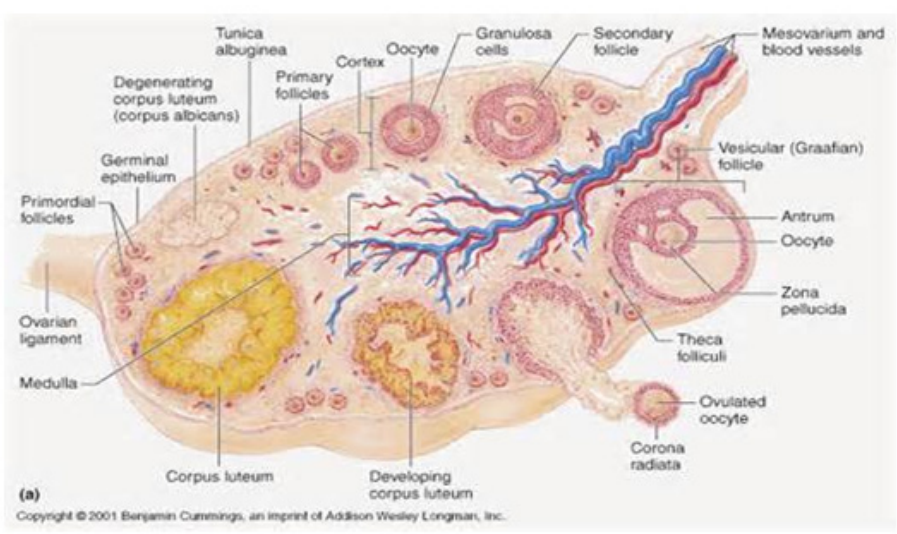

Figure 2 Ovary.

\section{Follicular (preovulatory, estrogenic) phase}

It entails maturation of the ovarian follicle and secretion of estrogen hormone. Under the effect of the follicle stimulating hormone (F.S.H.) secreted by the anterior pituitary gland, many primary ovarian follicles grow at the same time, but only one of them reaches full maturation into a Graafian follicle. The other follicles undergo atresia (atretic follicles).The developing Graafian follicle secretes estrogen in the liquor folliculi. Estrogen is responsible for the proliferative phase of the uterine cycle.

\section{Ovulation}

It is the process of rupture of the Graafian follicle and release of the mature ovum from the ovary. It occurs once every lunar month (about 28days) during the fertile period of the human female. It does not occur during pregnancy. It sometimes occurs during lactation. The time of ovulation is variable but it is usually on the $14^{\text {th }}$ day of the ovarian cycle. Ovulation occurs at about 14days ( \pm one day) before the beginning of the next menstruation. The cause of ovulation is attributed to inhibition of F.S.H. and stimulation of L.H. secretion by the anterior pituitary gland leading to an increased salt concentration of the liquor folliculi, resulting in an increase in its osmotic pressure and rupture of the Graafian follicle.

\section{Luteal (postovulatory, progestational) phase}

It entails formation of the corpus luteum and secretion of progesterone hormone. Following ovulation, the ovarian follicle passes into the following stages:

\section{The corpus hemorrhagicum}

After ovulation, the wall of the ovarian follicle collapses and becomes folded due to sudden release of the pressure inside it. Bleeding occurs inside the follicle with the formation of a blood clot. Corpus hemorrhagicum lasts for about three days before it changes into corpus luteum.

\section{The corpus luteum}

The ruptured follicle is gradually transformed into the corpus luteum. The granulose cells enlarge, become polyhedral and develop a yellowish carotenoid pigment (the lutein). Now, the cells are termed the granulose luteal cells. At the same time, the theca interna cells undergo similar changes and become the caluteal cells. The capillaries grow among the luteal cells allowing gradual absorption of the blood clot inside the follicle. The corpus luteum has the function of secreting progesterone and small amounts of estrogen. This yellow body has one of two fates. If there is no fertilization, it persists for 9-14days (corpus luteum of menstruation), then rapidly degenerates to give rise to the corpus albicans (the fibrous body). If fertilization occurs, the corpus luteum persists for 4 months (corpus luteum of pregnancy), then slowly degenerates, and its function is taken by the placenta. The persistence of the corpus luteum of pregnancy is induced by the chorionic gonadotropin, which is secreted by the placenta.

\section{Hormonal control of the ovarian cycle}

In the first half of the cycle, the anterior pituitary gland secretes follicle-stimulating hormone (F.S.H.) that causes maturation of the primary ovarian follicle to the mature Graafian follicle, and consequently secretion of estrogen by the Graafian follicle. In the middle of the cycle, estrogen inhibits F.S.H. secretion and stimulates the secretion of the luteinizing hormone (L.H.) and the luteotrophic hormone (L.T.H.) by the anterior pituitary gland, and both hormones cause ovulation. In the second half of the cycle, L.H. changes the corpus hemorrhagicum into corpus luteum. L.T.H. stimulates the corpus luteum to secrete progesterone and small amount of estrogen. Progesterone inhibits the production of L.H. and L.T.H. leading to regression of the corpus luteum. Decreased estrogen level stimulates F.S.H. secretion and a new cycle starts.

\section{The uterine (endometrial, menstrual) cycle}

It occurs in the endometrium of the uterus depending on the hormonal changes that occur in the ovarian cycle. It has four phases: menstrual, regenerative, proliferative and secretory phases. The cycle duration extends from the first day of one menstruation to the first day of the next menstruation, in most typical cycles it is about 28days but it may normally vary from 21 to 40days.

\section{Menstrual phase (menstruation, menses)}

Degeneration of the corpus luteum at the end of the ovarian luteal phase leads to a decreased level of progesterone and estrogen with the result of a temporary spasm of the spiral arteries supplying the superficial $2 / 3$ of the endometrium, and ischemia and necrosis of the endometrium and walls of the capillaries occur. When the spasm is relieved, blood escapes from the damaged capillaries and it flows with the necrosed endometrium (menses). The source of the menstrual flow comes from the endometrium above the level of the cervix. The cervix and the uterine tubes do not share in the menstrual flow. The superficial layers (stratum compactum and stratum spongiosum) are the only parts of the endometrium that shed off. At the end of this phase, the endometrium is about $0.5 \mathrm{~mm}$ thick. The average duration of menstruation is $3-5$ days. The menstrual flow is constituted of 
epithelial cells (endometrial casts) and blood, which is about 50-60cc in volume and does not clot due to the presence of proteolytic enzymes destroying the proteins needed for coagulation of the blood. Variations of the menstrual phase include amenorrhea (no menstruation as in pregnancy), menorrhagia (increased menstrual flow), oligomenorrhea (decreased menstrual flow) and polymenorrhea (increased frequency of menstruation) (Figure 3).

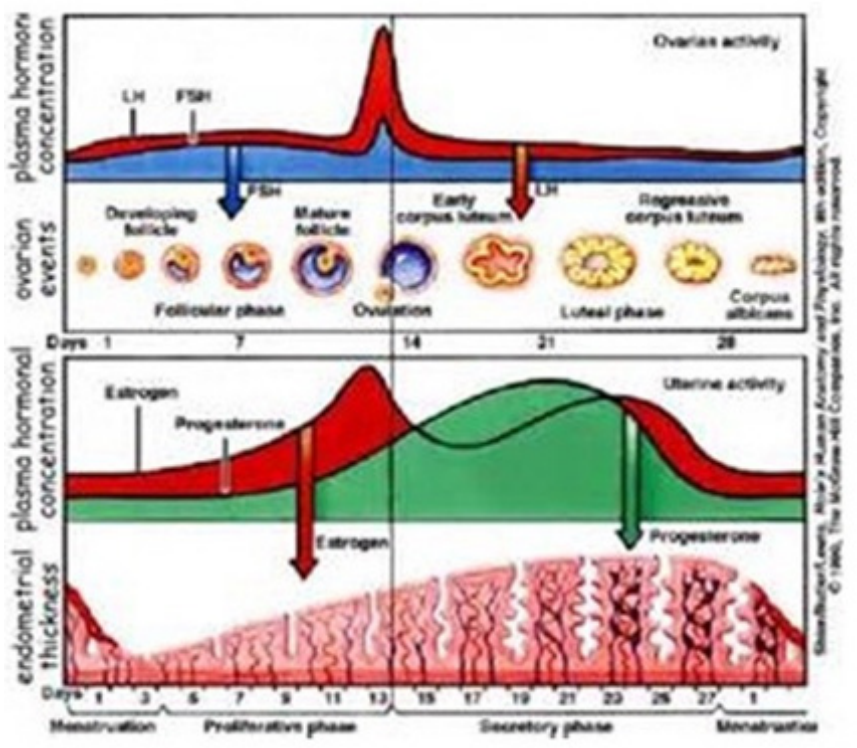

Figure 3 Ovarian and menstrual cycle.

\section{Regenerative phase (repair)}

From the fourth to the sixth day of the cycle, regeneration of the endometrium is carried out by the stratum basale. The epithelium of the fundi of the glands proliferates to complete the epithelial lining of the denuded mucous membrane. At the end of this phase, the epithelium reaches thickness of $2 \mathrm{~mm}$ and is flat. The endometrial glands are straight and narrow. The endometrial strom a contains lymphocytes and spindle-shaped connective tissue cells.

\section{Proliferative (follicular, postmenstrual, estrogenic) phase}

It occurs from the seventh to the fifteenth day of the cycle. It corresponds to the follicular phase of the ovarian cycle. It is under the control of estrogen secreted by the ovarian (Graafian) follicle. The endometrium proliferates, increases in thickness $(4 \mathrm{~mm})$ and its lining is cuboidal. The uterine glands are straight, long and widely separated with no or little secretion.

\section{Secretory (luteal, premenstrual, progestational) phase}

It occurs from the $16^{\text {th }}$ to the $28^{\text {th }}$ day of the cycle. It corresponds to the luteal phase of the ovarian cycle. It is under the control of progesterone secreted by the corpus luteum. The endometrium is thick $(10 \mathrm{~mm})$, soft, velvet, and is loaded with water. It is columnar and differentiated, at the end of this phase, into three strata:

i. Stratum compactum (superficially): It is a compact layer containing the necks of the uterine glands. ii. Stratum spongiosum (in the middle): It is a loose (edematous) layer containing the bodies of the uterine glands.

iii. Stratum basale (deeply): It is a thin basal layer containing the fundi of the uterine glands. It is responsible for regeneration of the shed endometrium. In this phase, the uterine glands are tortuous, spiral (corkscrew) and loaded with secretion, which is rich in mucin and glycogen. The arteries supplying the endometrium are of two types: short straight basal arteries (limited to the stratum basale) and long superficial spiral arteries (extending through the whole depth of the endometrium and are the main vessels of the endometrium).

\section{Clinical aspects}

Obesity, malnutrition and weight loss are reported to be associated with decreased fecundity in women. Impaired reproduction in obese women is often due to an ovulation. However, obese women with ovulatory cycles also have reduced fertility possibly because obesity has a direct negative impact on the oocyte and embryo quality as well as on the endometrial receptivity. ${ }^{5}$ Experimentally, it was discovered that stress-reactive (high-avoidance) female rats had a shorter reproduction lifespan than stress-nonreactive (low-avoidance) female rats. ${ }^{6}$ It has been also observed that ovarian response to controlled ovarian stimulation is not impaired by maternal thalassemia carrier status and that embryo biopsy did not impair the pre-implantation embryo development or pregnancy outcomes. ${ }^{7}$

\section{Acknowledgements}

None.

\section{Conflict of interest}

The author declares no conflict of interest.

\section{References}

1. Moore KL, Persaud TVN, Torchia MG. The Developing Human: Clinically Oriented Embryology. 10th ed. Saunders, Philadelphia, USA; 2015. p. $1-560$.

2. Schoenwolf GC, Bleyl SB, Brauer PR, et al. Larsen's Human Embryology. 5th ed. New York, USA: Churchill Livingstone; 2015. p. 1-576.

3. Moore KL, Persaud TVN, Torchia MG. Before We Are Born: Essentials of Embryology and Birth Defects. 7th ed. Philadelphia, USA: Saunders/ Elsevier; 2015. p. 1-368.

4. Sadler TW, Thomas W, Langman J. Langman's Medical Embryology. 11th ed. Wolters Kluwer, Philadelphia: Lippincott Williams \& Wilkins; 2010. p. 1-385.

5. Kuokkanen S, Polotsky AJ, Chosich J, et al. Corpus luteum as a novel target of weight changes that contribute to impaired female reproductive physiology and function. Syst Biol Reprod Med. 2016;62(4):227-242.

6. Ohta R, Kumagai F, Marumo H, et al. Stress-reactive rats (high-avoidance female rats) have a shorter lifespan than stress-nonreactive rats (low-avoidance female rats). J Toxicol Pathol. 2016;29(2):77-84.

7. Yuan Y, Yuan X, Zhou C. Does thalassemia influence ovarian response? An analysis of 127 cycles involving pre-implantation genetic diagnosis of thalassemia in southern China. J Obstet Gynaecol. 2016;12:1-5. 